\title{
Influência da glutamina na regeneração hepática
}

\section{Glutamine influence on liver regeneration}

\author{
Maria de Lourdes Pessole Biondo-Simões', Jorge Eduardo \\ Fouto Matias ${ }^{2}$, Daniel Martone ${ }^{3}$, Rafael Faria Barbosa ${ }^{3}$, \\ Gustavo Higa Ogawa ${ }^{3}$
}

\begin{abstract}
Biondo-Simões, MLP, Matias JEF, Martone D, Barbosa RF, Ogawa GH. Influência da glutamina na regeneração hepática. Rev Med (São Paulo). 2007 out.-dez.;86(4):219-23.

RESUMO: Objetivo: Este trabalho visa estabelecer a relação mais precisa do uso da glutamina na regeneração hepática. Métodos: Foram utilizados 37 ratos da linhagem Wistar, fêmeas, com idade de 120 dias e peso entre $345 \pm 80$ gramas os quais foram divididos em um grupo controle (C), com 17 animais, e um grupo de experimento (E), com 20 animais. Aproximadamente $70 \%$ do fígado foi cirurgicamente removido nos dois grupos. Administraram-se 50 $\mu \mathrm{g}$ de glutamina/dia, via oral, diluído em $1 \mathrm{ml}$ de água destilada, administrado por sondagem orogástrica diária no grupo de experimentação. No grupo controle, administrou-se volume equivalente de água destilada. As aferições foram feitas nos períodos de 24 horas e 7 dias, com 3 métodos: Fórmula de KWON et al para reconhecer ganho de volume, contagem das figuras de mitose em 5 campos e percentual dos núcleos PCNA positivos em 5 campos. Resultados: O remanescente hepático ganhou maior volume nos dois grupos tanto com 24 horas $(p>0,05)$ quanto com 7 dias $(p=0,0518)$. Os cortes histológicos revelaram mais figuras de mitose com 24 horas, tanto no grupo controle quanto no grupo experimento. A contagem dos núcleos PCNA positivos, com 24 horas, foi maior nos cortes dos fígados do grupo experimento em relação ao grupo controle $(p<0,001)$; enquanto não apresentou grandes mudanças, em 7 dias, para ambos os grupos $(p>0,05)$. Conclusão: A suplementação de glutamina à dieta leva à maior replicação de hepatócitos com 24 horas. Logo, é benéfica para a regeneração hepática.
\end{abstract}

DESCRITORES: Regeneração hepática. Glutamina. Hepatectomia.

\footnotetext{
1. Doutora em Cirurgia Experimental pela Universidade Federal de São Paulo (UNIFESP-EPM). Professora Titular de Metodologia da Pesquisa da PUCPR, Professora Adjunta do Departamento de Cirurgia da Universidade Federal do Paraná (UFPR), Titular do Colégio Brasileiro de Cirurgiões.

2. Professor titular da Disciplina de técnica cirúrgica e cirurgia experimental UFPR.

3. Acadêmico de Medicina da Universidade Federal do Paraná (UFPR).

Endereço para correspondência: Daniel Martone. Rua Padre Anchieta 4446, Ap. 16. BIGORRILHO. Curitiba, PR. CEP: 80430-060. e-mail: daniel_martone@yahoo.com.br
} 


\section{INTRODUÇÃO}

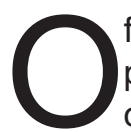
fígado é um órgão que quando perde parte de seu parênquima tem capacidade de regeneração. Em outras palavras, o fígado consegue restaurar a massa hepática perdida através de uma hiperplasia global do parênquima restante. Porém, neste intervalo de tempo em que a massa hepática se recompõe, há um período de insuficiência hepática.

Portanto, o estudo da regeneração hepática e de fatores que podem acelerar ou retardar esse processo tem uma importante relevância para a área médica. Tanto é verdade que vários autores têm buscado pesquisar agentes que, de certa forma, contribuam para a regeneração. Michalopoulos ${ }^{12}$ classificou esses agentes em dois grupos: os mitogênicos completos e os incompletos (co-mitogênicos). Entre os agentes mitogênicos completos tem-se: a) o fator de crescimento epidêmico (EGF); b) fator de crescimento do hepatócito (HGF); c) o fator transformador do crescimento alfa (TGF- $\alpha$ ); d) a substância estimuladora hepática (HSS); e) o fator de crescimento de fibroblastos ácido (FGF- $\alpha$ ) e f) o hormônio do crescimento. Entre os co-mitogênicos tem-se: a) norepinefrina e receptor adrenérgico, b) vasopressina e angiotensinas, c)insulina e glucagon, d) prostaglandinas (ácido araquidônico, $P \mathrm{FA}_{1}, \mathrm{PGE}_{1}$, $\mathrm{PGE}_{2}$ e $P \mathrm{PG}_{2}{ }^{\alpha}$, e) estrógeno e testosterona e f) fibronectina.

\section{MÉTODOS}

Foram utilizados 37 ratos (Rattus norvegicus albinus, Rodentia mammalia), Wistar, fêmeas, com idade de 120 dias e peso entre $345 \pm 80$ gramas, mantidos em biotério com ciclo claro-escuro, temperatura e umidades próprios do ambiente, com livre acesso à água e à ração.

A amostra foi dividida em 2 grupos: um contendo 17 ratos para constituir o grupo controle (C) e outro contendo 20 ratos para constituir o grupo de experimento (E). Sob anestesia obtida com um mililitro para $100 \mathrm{~g}$ de peso de uma solução de um mililitro de quetamina $(50 \mathrm{mg}) \mathrm{com}$ um mililitro de xilazina (20mg), por injeção intramuscular, feita na para traseira direita. Os animais de ambos os grupos foram submetidos à depilação digital da parede abdominal ventral e anti-sepsia com polivinilpirrolidona-iodo. Em seguida foram realizadas laparotomias medianas com hepatectomias parciais, ressecando-se os lobos lateral esquerdo e mediano. Essa hepatectomia equivale à ressecção de aproximadamente $67 \%$ do volume da víscera (Higgins e Anderson, 1931). Os segmentos ressecados foram pesados e anotados em protocolo. Após a laparorrafia administrou-se $50 \mu \mathrm{g}$ de glutamina ao dia, por via oral diluído em $1 \mathrm{ml}$ de água destilada administrado por sondagem orogástrica diária e nos do grupo controle administrou-se volume equivalente de água destilada. As aferições foram realizadas em até 36 horas e com 7 dias, quando foram sacrificados 8 animais de cada grupo. Desta forma, obtiveram-se os subgrupos $C_{1}, C_{2}, E_{1}$ e $E_{2}$. Os ratos foram pesados novamente e realizou-se nova laparotomia com ressecção total do fígado que foi pesado. As medidas foram anotadas em protocolo.

As peças ressecadas foram fixadas em formalina tamponada a $10 \%$ e encaminhadas para estudo histopatológico, corando-se os cortes histológicos pela hematoxilina e eosina.

A regeneração foi avaliada através de 2 métodos: pela fórmula de Kwon et al. e pela contagem das figuras de mitose existentes em 10 campos.

A fórmula de Kwon et al. fornece a taxa de regeneração, baseada no peso.

$$
\%=\mathrm{D} / \mathrm{E} .100 \text { onde } \mathrm{E}=\mathrm{R} / 0,7
$$

onde:

$$
\begin{aligned}
& \mathrm{D}=\text { peso do fígado por } 100 \mathrm{~g} \text { de peso do animal } \\
& \text { no dia do sacrifício; } \\
& \mathrm{E}=\text { representa o peso estimado por } 100 \mathrm{~g} \text { de } \\
& \text { peso do animal, antes da hepatectomia, a qual é } \\
& \text { calculada pelo peso do fígado ressecado (R). }
\end{aligned}
$$

Os resultados foram submetidos à análise estatística através do teste não paramétrico de Mann Whitney para comparação entre dois grupos, nos dois tempos. O nível de significância adotado foi $p$ 0,05 ou $5 \%$.

\section{RESULTADOS}

O remanescente hepático ganhou maior volume nos animais dos dois grupos tanto com 24 horas $(p>0,05)$ quanto com 7 dias $(p=0,0518)$ (Gráfico 1). Os cortes histológicos revelaram que com 24 horas havia mais figuras de mitose, tanto no grupo controle quanto no grupo de experimento. A contagem dos núcleos PCNA positivos, com 24 horas, foi maior nos cortes dos fígados do grupo de experimento em relação ao grupo controle $(p<0,001)$; enquanto não apresentou grandes mudanças, em 7 dias, para ambos os grupos $(p>0,05)$ (Gráfico 2). 


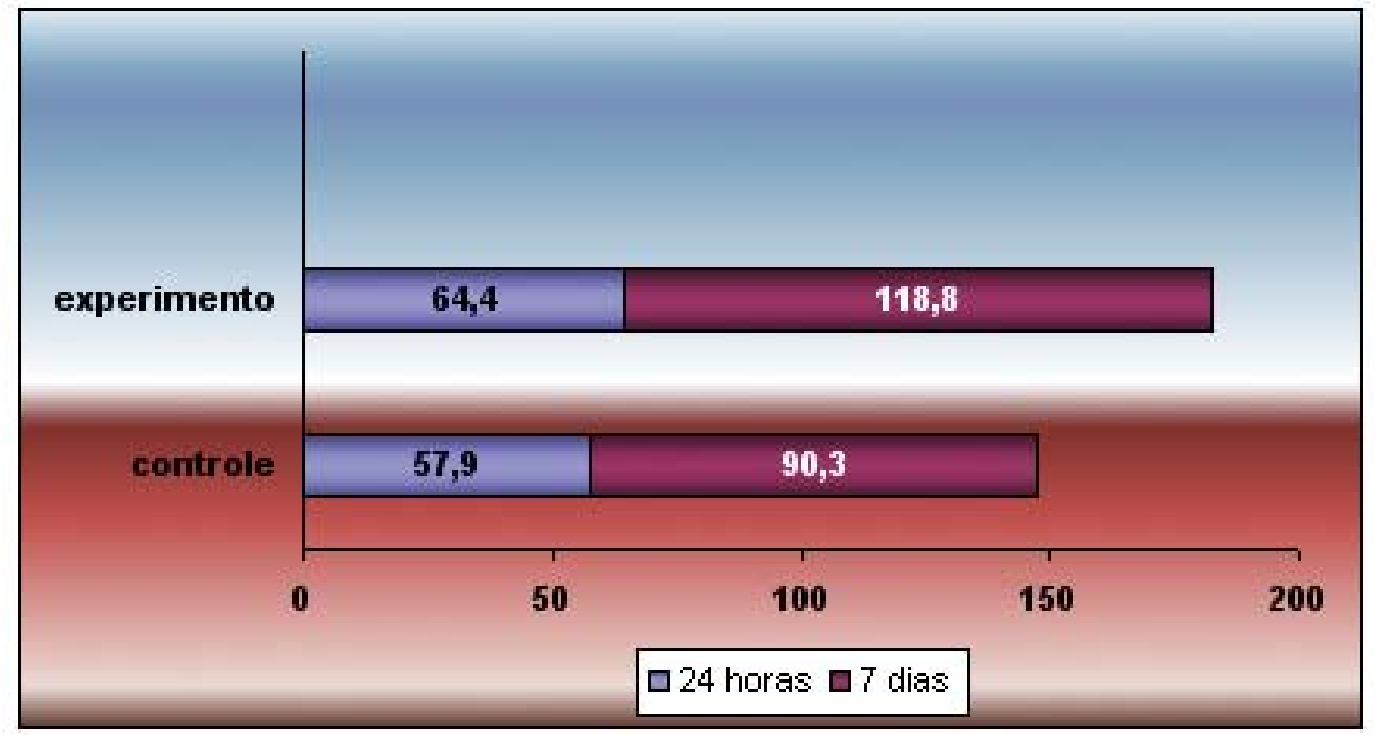

Grafico 1. Média da porcentagem de regeneração hepática em grupo controle e grupo de experimento em $24 \mathrm{~h}$ e com 7 dias de evolução.

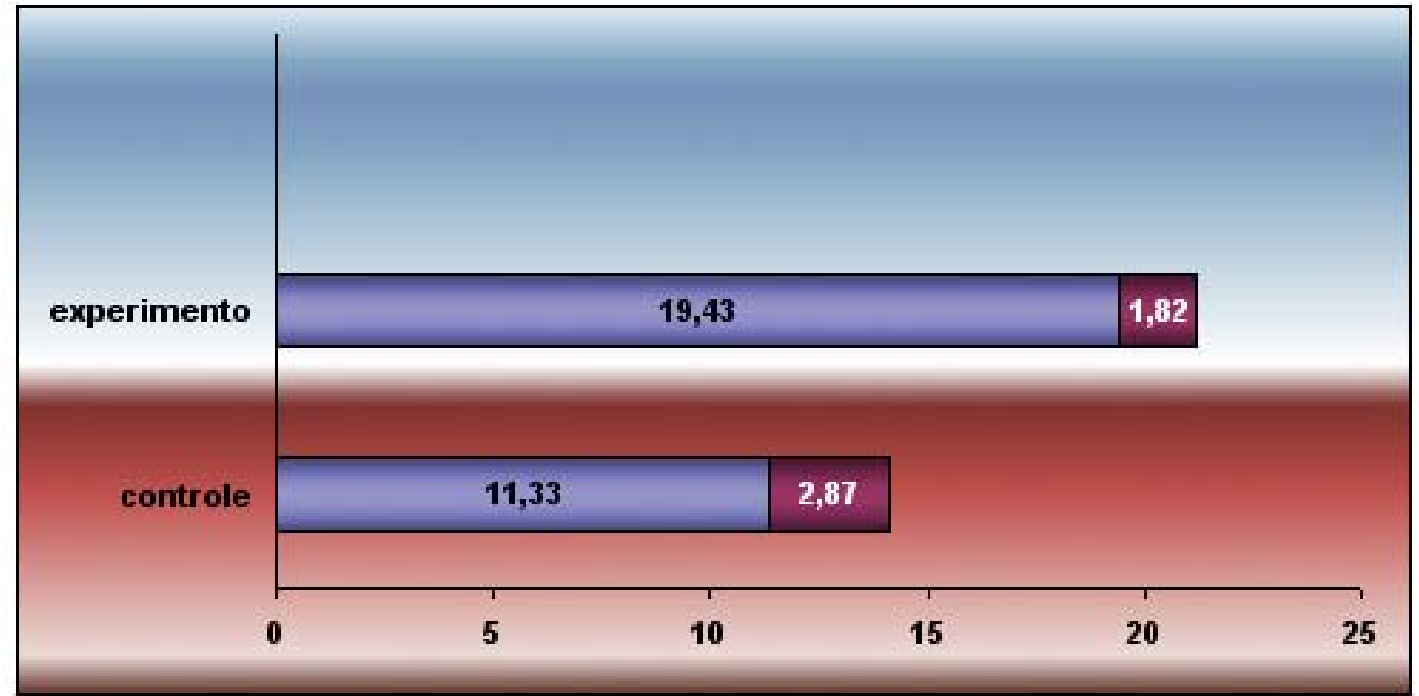

Gráfico 2. Média de núcleos PCNA positivos, em 5 campos, de grupo controle e grupo de experimento com 24 h e 7 dias de evolução.

\section{DISCUSSÃO}

A glutamina tem sido apontada como possuidora de propriedades favoráveis à regeneração de inúmeros tecidos orgânicos, dentre os quais encontra-se o tecido hepático. Trata-se do aminoácido encontrado em maior abundância no organismo humano motivo pelo qual o estudo de suas propriedades tem ganhado cada vez mais importância na literatura médica atual. Alguns autores apontam tratar-se de um importante fator no metabolismo de proteínas e outros aminoácidos em situações de stress, situações nas quais foi constatado que seus níveis séricos encontravam-se diminuídos.

Ademais, tem-se verificado um efeito negativo da glutamina na translocação bacteriana, comum em processos regenerativos orgânicos, e a qual retarda o processo regenerativo. Um possível mecanismo de ação para tanto seria a elevação dos níveis sistêmicos de $\lg A$ produzidas por este aminoácido.

Outro possível mecanismo relevante seria a atual constatação da diminuição da expressão 
celular de moléculas de adesão (CAM ), causado pela glutamina, assim como uma inibição da migração endotelial dos neutrófilos o que por si só retarda o processo regenerativo tissular.

Esses fatores são, provavelmente, os responsáveis pelo incremento no número de células em replicação em 24 horas verificado no grupo de experimento de nosso trabalho, acompanhado pelo aumento do ganho de massa hepática observado no mesmo, no que tange ao período de 7 dias de experimento.

Todavia, o grupo controle também apresentou regeneração tissular, o que pode ser explicado pela influência de outros fatores no processo de regeneração. Dentre esses fatores estão certos grupos de interleucinas, hormônios derivados do intestino e peptídeos conforme apontado por alguns autores.

Ainda, no grupo de experimento com 24 horas não apresentou ganho estatisticamente relevante de massa tissular hepática o que nos faz pensar em outros possíveis fatores que interferem negativamente nesse processo tais como o curto espaço de tempo para a ação da glutamina administrada, reduções do fluxo sanguíneo, adesões bacterianas à superfície intestinal, alterações hemodinâmicas no sistema porta decorrentes da hepatectomia, oclusões intestinais e etc.

Tais dados nos permitem afirmar que a suplementação de glutamina à dieta leva à maior replicação de hepatócitos com 24 horas. Logo, é benéfica para a regeneração hepática.

Biondo-Simões, MLP, Matias JEF, Martone D, Barbosa RF, Ogawa GH. Glutamine influence on liver regeneration. Rev Med (São Paulo). 2007 out.-dez.;86(4):219-23.

\begin{abstract}
Objective: The aim of this work is to establish a precise relation between the use of glutamine and hepatic regeneration. Methods: 37 rats of the Wistar ancestry were used, females, with age of 120 days and weight between $345 \pm 80$ grams, which were divided in a control group (C), with 17 animals, and an experimental group (E), with 20 animals. Approximately $70 \%$ of the liver was surgically removed in these two groups. $50 \mu \mathrm{g}$ of glutamine/day was managed, orally, diluted in $1 \mathrm{ml}$ of distilled water, managed by daily gavage in the experimental group. In the control group, distilled water was managed in equivalent volume. The contings were made in the periods of 24 hours and 7 days, by 3 methods: Formula of KWON et al to recognize volume gain, mitoses figures counting in 5 fields and PCNA positive nucleus percentage in 5 fields. Results: The remainder hepatic tissue gained greater volume in the two groups as much in the period of 24 hours $(p>0,05)$, as in 7 days $(p=0,0518)$. The histological cuts have disclosed more figures of mitoses in 24 hours, as much in the group control as in the group experiment. The counting of positive nucleus PCNA, in 24 hours, was bigger in the livers cuts of the experiment group in relation to the group control $(p<0,001)$; although it has not presented great changes, in 7 days, in both the groups ( $>>0,05)$. Conclusion: The supplementation of glutamine to the diet leads to the biggest response of hepatocytes within 24 hours. Consequently, it is beneficial for hepatic regeneration.
\end{abstract}

KEY WORDS: Liver regeneration. Glutamine. Hepatectomy.

\section{REFERÊNCIAS}

1. Assy N, Minuk GY. Liver regeneration: Methods for monitoring and their applications. J Hepatol. 1997;26(4): 945-52.

2. Barrata B, Rizzoli R, Galliani I, Vitale M. Early events of liver regeneration in rats: a multiparametric analysis. Histochem Cell Biol. 1996;105(1): 61-9.

3. Beyer HS, Sherman R, Zieve L. Aging is associated with reduced liver regeneration and diminished thymidine kinase mRNA content and enzyme activity in the rat. J Lab Clin Med. 1991;117(2):102-8.

4. Biondo-Simões MLP, Greca FH, Techy F, Soares DP,
Kannenberg C, Castro CCL, et al. Efeito da histamina na regeneração hepática: estudo experimental em ratos. Acta Cir Bras. 2000;15(1).

5. Brand HS, Deutz NE, Meijer AJ, Jorning GG, Chamuleau RA. In vivo amino acid fluxes in regenerating liver after two-thirds hepatectomy in the rat. J Hepatol.1995;23(3):333-40.

6. Contran RS, et al. Patologia estrutural e functional. Rio de Janeiro: Guanabara Koogan; 2002.

7. Cressman DE, Diamond RH, Taub R. Rapid activatin of the start 3 transcription complex in the liver 
regeneration. Hepatology. 1995;21:1443-9.

8. Ito A, Higashiguchi T. Effects of glutamine administration on liver regeneration following hepatectomy. Nutrition. 1999;15(1):23-8.

9. Jesus RP de, Waitzberg DL, Campos FG. Regeneração hepática: papel dos fatores de crescimento e nutrientes. Rev Assoc Med Bras. 2000;46(3):242-54.

10. Kalil NA, Sperb D, Lichtenfels E. Efeito da pilocarpinana regeneração hepática pós hepatectomia parcial em ratos. Acta Cir Bras. 1998:13(4):222-6.

11. Labrecque D. Liver regeneration: a picture emerges from the puzzle. Am J Gastroenterol. 1994;89:S86-S96.

12. Michalopoulos G. Liver regenaration: molecular mechanisms of growth control. Faber J. 1990;4:176-87.

13. Michalopoulos G, DeFrances MC. Liver regeneration. Science. 1997;276:60-6.

14. Ramalho FS. A regeneração hepática e os inibidores da enzima conversora da angiotensina. Acta Cir Bras., 2000;15 supl. 2:14-7.

15. Ramalho FS, Ramalho LNZ, Zucoloto S, Castro e Silva
JR O. Regeneração hepática: algumas definições num universo de incertezas. Acta Cir Bras. 1993;8:177-89.

16. Skullman S, Wiren M, Chu M, Permert J, Garlick Pj, Mcnurlan Ma, et al. Effects of graded glutamine intake on liver protein metabolism following partial hepatectomy. Eur J Gastroenterol Hepatol. 1995;7(9):881-6.

17. Wang J, Jia Q, Wu Y, Yan L. Influence of different total parenteral nutrition support upon hepatic regeneration after partial hepatectomy in rats. Hua Xi Yi Ke Da Xue Xue Bao. 1999;30(3):299-300, 303.

18. Westwick JK, Weitzel C, Lerrert HL, Brenner DA. Activation of jun kinase is a early event in hepatic regeneration. J Clin Invest. 1995;95:803-10.

19. Yamaguchi $T$, Minor $T$, Isselhard $W$. Effect of glutamine or glucagon-insulin enriched total parenteral nutrition on liver and gut in $70 \%$ hepatectomized rats with colon stenosis. J Am Coll Surg. 1997;185(2):156-62.

20. Yoshida S, Yunoki T, Aoyagi K, Ohta J, Ishibashii N, Noake $\mathrm{T}$, et al. Effect of glutamine supplement and hepatectomy on DNA and protein synthesis in the remnant liver. J Surg Res. 1995;59(4):475-81. 